\title{
Mancozeb: growing risk for agricultural communities?
}

\author{
The short- and long-term health consequences of pesticides are real
}

\author{
Kishor Atreya and Bishal K Sitaula
}

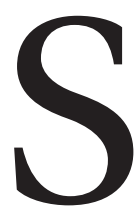

ince the 1950s, when DDT was introduced in Nepal for the purpose of malaria control, many other pesticides have been registered for use. Chemical pesticides are used by $25 \%$ of Terai households, 9\% of mid-hill households, and $7 \%$ of mountain households (CBS 2003). In certain mid-hill pockets close to urban markets, the penetration of pesticide use is considerably higher. The incorporation of vegetables into Nepal's cereal-based agricultural production system, especially in the hills, has stimulated a significant demand for chemical inputs such as pesticides. Although pesticide import declined after 2002, that trend has apparently reversed, with import substantially increasing in 2007 and 2008 (Table 1). Assuming all the imported pesticide is consumed, the pesticide use at national level for the year 2008 was $151.2 \mathrm{~g}$ active ingredient per ha of arable land (total arable land =2,357,000 ha; UN [2010]).

Chemical pesticides are known to have deleterious effects on human health and on the environment. A series of studies (e.g., Dahal 1995, Pujara and Khanal 2002, Atreya 2007a, b, c, 2008a, b), highlighting the massive use of chemicals in vegetable growing areas has raised the issue of possible health risks for our agrarian communities. Studies conducted abroad have linked mancozeb, a synthetic pesticide, to serious hazards including cancer. Now we have evidence that farmers are applying mancozeb at levels significantly exceeding the manufacturer's recommendations (Atreya 2007c, 2008b).

Mancozeb, a grayish-yellow powder, is used to control fungal diseases that afflict many important economic crops, including potato, tomato, fruits and flowers. It is a broadspectrum pesticide that indiscriminately kills a range of organisms, targeted as well as untargeted (and beneficial) species. It acts by disrupting lipid metabolism. It has low volatility at standard temperatures and pressure but can be found associated with air-borne particulates or as spray drift. In a moist environment, it hydrolyzes into ethylenethiourea (ETU), ethyleneurea (EU) and ethylene bisisothiocyanate sulfide (EBIS) with a half-life of less than 2 days. In moisturelimited soil conditions, the half-life is $2-7$ weeks. The World Health Organization (WHO 2005) classified it as "nonhazardous under normal use.' Mancozeb enters into body mainly through the skin and from inhalation. Baldi et al. (2006) observed the highest contamination through the hands.

Vegetable farming, an important source of revenue in the hills of Nepal, generally entails heavier applications of pesticides than does cereal farming. In Nepal, a few studies have shown that households apply more than $90 \%$ of the total pesticides into vegetable farming. Atreya (2008b) investigated
In a country where farmers rely on conventional wisdom to make decisions on farming practices and the government lacks clear policies based on solid research, pesticide overuse is emerging as a problem. Mancozeb, the widely applied pesticide in Nepal's vegetable farming, has both short- and long-term health consequences to people exposed to its unsafe levels. A handful of studies in the hill regions of Nepal suggest that the pesticide is being sprayed to farms at much higher level than recommended. The widespread misuse and dangerous consequences of this pesticide suggest a need for more thorough study, better instruction, and more effective control.

3637 spray operations performed by 291 households in two VDCs of Kavre district. In 3464 of those operations, mancozeb was used either alone or in combination with other pesticides, making it the most widely used of the sixteen pesticides studied.

Due to its low acute toxicity and short environmental persistence, the amount of mancozeb used is increasing worldwide (Colosio et al. 2002), and so far there are no recorded incidents of acquired resistance to the chemical. In Nepal, mancozeb is marketed under various commercial names such as Dithane M-45 75\% wettable powder (WP), Kishan M-45 75\% WP, Indofil M-45 75\% WP. Mancozeb is also marketed in combination with $8 \%$ metalaxyl as Krinoxyl Gold $72 \%$ WP and Matco 72\% WP.

Farmers use mancozeb primarily to control late blights of potato and tomato at 5-7 day intervals, although a study claims that a 14-day interval application at the recommended dose is sufficient for the purpose (Apel et al. 2003). The recommended dose for control of potato blight is 11251500 grams of mancozeb dissolved in 750 liters of water per hectare, at regular intervals of 7-10 days (PRMS 2006). This amounts to a concentration of 1.5-2 grams/liter. It is generally agreed that mancozeb is being used at levels exceeding this recommendation. For instance, Atreya (2007c) calculated the

Himalayan Journal of Sciences 6(8): 9-10, 2010

doi: 10.3126/hjs.v6i8.1794; published online: Nov 04, 2010 Copyright@2010 by Himalayan Association for the

Advancement of Science 
Table 1. Pesticide's active ingredients import in Nepal ('000 kg)

\begin{tabular}{|lllllll|}
\hline Year & $\begin{array}{l}\text { Insecti- } \\
\text { cides }^{+}\end{array}$ & $\begin{array}{l}\text { Fungi- } \\
\text { cide }\end{array}$ & $\begin{array}{l}\text { Herbi- } \\
\text { cides }\end{array}$ & $\begin{array}{l}\text { Roden- } \\
\text { ticides }\end{array}$ & $\begin{array}{l}\text { Oth- } \\
\text { ers }^{++}\end{array}$ & Total \\
\hline 1999 & 43.46 & 54.53 & 2.68 & 4.06 & 3.69 & 108.43 \\
\hline 2000 & 62.44 & 102.77 & 14.94 & 3.42 & 12.48 & 196.06 \\
\hline 2001 & 60.32 & 75.44 & 3.26 & 4.30 & 2.83 & 146.15 \\
\hline 2002 & 60.39 & 90.57 & 6.84 & 1.24 & 18.55 & 177.59 \\
\hline 2003 & 85.61 & 55.20 & 11.24 & 7.87 & 16.46 & 176.37 \\
\hline 2004 & 35.36 & 97.04 & 6.39 & 1.14 & 14.17 & 154.08 \\
\hline 2005 & 65.00 & 47.70 & 11.03 & 1.46 & 6.08 & 131.27 \\
\hline 2006 & 46.55 & 74.37 & 5.70 & 1.81 & 2.85 & 131.28 \\
\hline 2007 & 60.28 & 237.37 & 6.57 & 37.30 & 5.97 & 347.49 \\
\hline $2008 *$ & 105.81 & 203.39 & 11.12 & 31.09 & 4.93 & 356.35 \\
\hline
\end{tabular}

+ includes organochlorines, organophosphates, synthetic pyrithroids, carbamates, botanical insecticides, mixed-insecticides, and other insecticides; ++ bactericides, acaricides, bio-pesticides, pesticide used in public health, and others

Source: Various official records of Pesticide Registration and Management Unit, Crop Protection Directorate, Department of Agriculture, Ministry of Agriculture; * Sabitri Baral, Pesticides Registrar, Office of the Pesticide Registrar, Kathmandu, Nepal.

average concentration of mancozeb as applied to vegetable crops in two VDCs of Kavre to be 4.26 grams per liter of water, more than twice the recommended concentration.

\section{Health effects}

Although it has been characterized as 'non-hazardous under normal use,' is less acutely toxic, and less persistent in the environment, it degrades into other products, of which ethylethiourea (ETU) is of greatest toxicological concern. ETU has been linked to sperm abnormalities (Cox 1996). It affects the central and peripheral nervous systems and causes endocrine disruption (Solomon et al. 2000). Many studies have confirmed that ETU is carcinogenic - particularly affecting the thyroid (Solomon et al. 2000, EPA 2001), teratogenic (interfering with embryonic development), and a general irritant (WHO 2005).

Nepal Government recommends that the maximum residue limit on food be $0.20 \mathrm{mg} / \mathrm{kg}$ food at maximum (CBS 2008). However, Nepal lacks toxicological studies on the mancozeb induced health hazards. A few survey based studies have revealed immediate and short-term effects from various pesticides. Farmers who spray pesticides suffer a range of symptoms. For those involved directly in pesticide applications, the predicted probability of acute illness in the day of operation is 0.41 (Atreya 2007c). Atreya (2008b) found that headache, skin and eye irritation and throat discomfort increase significantly with exposure to fungicides. The study calculates that the likelihood of developing headache and skin irritation after a single pesticide spray operation are $19 \%$ and $8 \%$, respectively.

The demand for pesticides in Nepal is likely to increase. A handful of studies show mancozeb to be the most widely used pesticide in Nepal. Studies around the world have documented a range of health hazards associated with it. Because farmers rarely use any kind of protection gear during spray operations, they are likely to expose themselves to unsafe concentration of pesticides. Long-term effects of the pesticide have not yet been studied in Nepal. However, the application of pesticides at levels much higher than those recommended entails serious risk. As most of the vegetables sold by farming families are grown by independent farmers who determine their own protocols for pesticide application without reference to standard recommendations, significantly high residues are likely to be passed on to consumers.

The authors are at Department of International Environment and Development Studies (Noragric), Norwegian University of Life Sciences (UMB), 1432, Aas, Norway.

e-mail: k.atreya@gmail.com (KA)

\section{References}

Apel H, MS Paudyal and O Richter. 2003. Evaluation of treatment strategies of the late blight Phytophthora infestans in Nepal by population dynamics modeling. Environmental Modeling and Software 18: 255-364

Atreya K. 2007a. Farmers' willingness to pay for community integrated pest management training in Nepal. Agriculture and Human Values 24: 399-409

Atreya K. 2007b. Pesticide use knowledge and practices: a gender differences in Nepal. Environmental Research 104(2): 305-311

Atreya K. 2007c. Pesticide use in Nepal: understanding health costs from short-term exposure. Kathmandu, Nepal: South Asian Network for Development and Environmental Economics. $26 \mathrm{p}$

Atreya K. 2008a. Health costs from short-term exposure to pesticides in Nepal. Social Science \& Medicine 67: 511-519

Atreya K. 2008b. Probabilistic assessment of acute health symptoms related to pesticide use under intensified Nepalese agriculture. International Journal of Environmental Health Research 18(3): 187-208

Baldi I, P Lebailly, S Jean, L Rougetet, S Dulaurent, P Marquet. 2006. Pesticide contamination of workers in vineyards in France. Journal of Exposure Science and Environmental Epidemiology 16: 115-124

CBS 2003. National sample census of Agriculture, Nepal, 2001/02: Highlights. Kathmandu, Nepal: Central Bureau of Statistics

CBS 2008. Environment statistics of Nepal 2008. Kathmandu, Nepal: Central Bureau of Statistics

Colosio C, S Fustinoni, S Birindelli, I Bonomi, G De Paschale, T Mammone et al. 2002. Ethylenethiourea in urine as an indicator of exposure to mancozeb in vineyard workers. Toxicology Letters 134: $133-140$

Cox C. 1996. Pesticides and male fertility: masculinity at risk. Journal of Pesticide Reform 16(2): 2-7

Dahal L. 1995. A study on pesticide pollution in Nepal. Kathmandu, Nepal: IUCN/Nepal

EPA [US Environmental Protection Agency]. 2001. The determination of whether dithiocarbamate pesticides share a common mechanism of toxicity. $46 \mathrm{p}$

PRMS [Pesticides Registration and Management Section]. 2006. Use pattern of registered pesticides. Kathmandu, Nepal: Nepal Government Department of Agriculture (in Nepali)

Pujara DS and NR Khanal. 2002. Use of pesticides in Jaishidhi subcatchment, Jhikhu khola watershed, Middle Mountain in Nepal. In: Hermann A and Schumann S (eds.), Proceedings: International workshop on environmental risk assessment of pesticides and integrated pest management in developing countries. Braunschweig, Germany: Landschaftsökologie und Umweltforschung. p 168-177

Solomon G, OA Ogunseitan and J Kirsch. 2000. Pesticides and human health: a resource for health care professionals. California, USA: Physicians for Social Responsibility and Californians for Pesticide Reform

UN [United Nations] . 2010. Statistical Yearbook - fifty third issue. UN Department of Economic and Social Affair, p 487-496

WHO 2005. The WHO recommended classification of pesticides by hazard and guidelines to classification: 2004. Rome, France: World Health Organization of the United Nations 